\title{
Application of neural networks modeling to environmentally global climate change at San Joaquin Old River Station
}

\author{
E. S. Salami ${ }^{1} \cdot$ M. Ehteshami ${ }^{2}$
}

Received: 28 January 2016/Accepted: 14 February 2016/Published online: 27 February 2016

(C) Springer International Publishing Switzerland 2016

\begin{abstract}
The present study focuses on temperature variations during the past 21 years (1990-2010) using data obtained from San Joaquin River (Old River Station), to calculate the rate of temperature variation. The rate of temperature change $(\mathrm{R})$ is calculated by adding up the difference between each year's mean temperature and that of the previous years. According to our calculation $\mathrm{R}$ equals to $0.0354{ }^{\circ} \mathrm{C} /$ year, which means that if the local conditions would exist, we will have $3.54{ }^{\circ} \mathrm{C}$ temperature rise within the next 100 years. Using the resource we calculated mean temperature for the past 21 years, which was equal to $17.12{ }^{\circ} \mathrm{C}$, meaning that the mean temperature of the year 2100 will be around $20.5{ }^{\circ} \mathrm{C}$, which will be incredibly high. We also made an ANN model (and ran it using MATLAB) to regenerate the missing data. The model is a feed-forward network with back propagation neurons trained by the Levenberg-Marquardt algorithm, with 4 layers containing 25 neurons. After making the model and before using it, we tested the model with existing data and compared the results that showed unexpected high correlation of $99 \%$.
\end{abstract}

Keywords Climate change $\cdot$ MATLAB $\cdot$ Artificial neural networks $\cdot$ Modeling

M. Ehteshami

Maehtesh@gmail.com

E. S. Salami

Esisalami@Yahoo.com

1 Environmental Engineering Department, University of Shiraz, Shiraz, Iran

2 Environmental Engineering Department, KN Toosi University of Technology, P.O Box 1587-544-16, Tehran, Iran

\section{Introduction}

The subjects of "global warming" and "climate change" have become part of both the popular lexicon and the public discourse. Applied environmental modeling has grown into a popular solution for today's environmental crises (Ehteshami et al. 1991; Ehteshami and Biglarijoo 2014; Yousefi et al. 2015). Discussions of global warming often evoke passionate responses and fierce debate between adherents to different views of the threat posed (Mann 2009; Zwolsman and Van Bokhoven 2007). There is a strong scientific consensus that the global climate is changing and that human activity contributes significantly (WMO 2013). It's also caused by increasing concentrations of greenhouse gases produced by human activities such as the burning of fossil fuels and deforestation. Today we can clearly see that the average temperature of Earth's atmosphere and oceans has increased since the late nineteenth century and the temperature rise is projected to continue. Since the early twentieth century, Earth's mean surface temperature has increased by about $0.8^{\circ} \mathrm{C}\left(1.4^{\circ} \mathrm{F}\right)$, and about two-thirds of that increase has occurred since 1980 (IPCC 2011). There are numerous models that have been made to predict the temperature (and its changes) in the next century. These models generate various results that depend on sensitivity of the model to the input parameters and also on the degree that human activities increase the level of greenhouse gases. Doran and Zimmerman (2009) in the Proceedings of the National Academy of Sciences of the United States reviewed publication and citation data for 1372 climate researchers. He concluded that 97-98\% of the most active climate researchers support the reality of human-caused climate change (Anderegga et al. 2010). Yet another survey reviewed articles published between 1993 and 2003 with the keyword being the phrase "global climate change". It found that none of the 928 
articles identified rejected the fact that humans have caused global warming. A 2009 survey by the American Geophysical Union found that $82 \%$ of the 3000 responding Earth scientists, and $97.4 \%$ of climate scientists, believe that human activity contributes to climate change (Doran and Zimmerman 2009).

There is no doubt that the primary cause of global warming is the concentration of greenhouse gases that is increasing and there are many scenarios for predicting the amount of that increase. However, according to an average scenario, carbon dioxide levels will increase by more than double from their pre-industrial level of roughly $280 \mathrm{ppm}$ in the atmosphere to about $700 \mathrm{ppm}$. Such an increase in greenhouse gas concentration would, in turn, lead to global warming of between 2 and $4{ }^{\circ} \mathrm{C}$, depending on the model (Mann 2009). Climate change can have many negative effects on the life of humans and the other creatures. For example, climate change increases water resources stress in some parts of the world where the runoff decreases, including around the Mediterranean basin, in parts of Europe, Central and Southern Americas, and Southern Africa. In other water-stressed parts of the world, particularly in Southern and Eastern Asia, climate change increases in runoff, but this may not be very beneficial in practice because the increase tends to come during the wet season and the extra water may not be available during the dry season (Arnell 2004).

In additional to impacts of climate change on the quantity of water resources, surface water quality is also affected by climate change (Delpla et al. 2009). According to what we said, there is a serious need to know the exact behavior of the climate. Even more than that, we must know the future prospect of the Earth's climate and temperature (including with regard to oceans and atmosphere). We must also analyze the related data and make model(s) to better understanding the changing climate behavior and finally (and in an ideal situation) control the unwanted impacts of climate change (by removing their causes). To monitor changes in the temperature, many scientific works have been done every year. For example, (Gutzler 2007), checked the temperature data for New Mexico in the twentieth century (1900-2005), noting that the total global temperature change in the twentieth century was about $1{ }^{\circ} \mathrm{F}$. According to some models for the 21st century, the global rise in annual temperature has been predicted at $3-7^{\circ} \mathrm{F}$. There are also representative charts that show increasing temperature in New Mexico during the present century. Some researchers have concentrated on the impacts of global warming in the past and the future. Other investigators, including (Arnell 2004), have studied the subject form a different angle. He worked on the effect of the population on water stress. He did not consider the impact of climate changes in the final result as he thought that in the absence of climate change, the future population in water-stressed watersheds would depend on population scenario. As a result, he concluded that by 2025 , the population in these watersheds will range from 2.9 to 3.3 billion people. He also analyzed the data produced by scenarios which were constructed using six climate models, run with the SRES (Special Report On Emissions Scenarios) to calculate changes in 30-year mean value of climate change pertaining to $1961-1990$ by the $2020 \mathrm{~s}$ (2010-2039), 2050s (2040-2069) and 2080s (2070-2099). Finally he came up with the following conclusions. Firstly, climate change increases water resources stress in some watersheds, but decreases it in others. And secondly, the estimated impact of climate change on global water resources depends least on the rate of future emissions, and most on the climate model that was used to estimate changes in climate. The assumed future population also plays a role. By the 2020s, 53-206 million people will move into the water-stressed category, while between 374 and 1661 million people are projected to experience an increase in water stress. Areas with an increase in water resources stress include the watersheds around the Mediterranean, in Central and Southern Africa, Europe, as well as Central and Southern America. Areas with an apparent decrease in water resources stress are concentrated in South and East Asia. Memzel and Matovelle (2010) also worked on the current and future situation of blue water availability, by reviewing its seven case scenarios.

According to what we have said so far, analyzing temperature data is necessary, So we try to find the most occur rate of temperature changing per year $\left({ }^{\circ} \mathrm{C} /\right.$ year $)$ would be able to show how the climate changes. A problem which probably happens when we analyze data is the loss of some necessary data in the information that we have obtained from various sources. If we just ignore the missing data, it can cause errors in the precision of our results. So it is better to reproduce the missing data one way or another. To do this, we can use models that have been already made [even by other researcher(s)]. However, even in this case, the difference between conditions of the model project and your project will lead to some errors. To obtain more accurate results, we can make a model based on the available data in order to estimate the missing data. Also, to make extra confidence about the results, we can take advantage of so many works that have been so far done on climate change based on Artificial Neural Network (ANN) model. Trigo and Palutikof (1999) proposed a non-linear neural network model that was initialized using output from general circulation model to build scenarios for daily temperature changes in Coimbra, Portugal, both for the present time (1970-1979) and the next decade (2090-2099). Hilbert and Ostendorf (2001) used an 
artificial neural network coupled with regional GIS (geographic information system) to assess the potential impacts of climate change on a complex landscape of tropical forests. (Knutti et al. 2003) proposed a neural networkbased climate model substitute that increases the efficiency of large climate model ensembles by at least an order of magnitude. They used the observed surface warming during the industrial period and estimates global ocean warming as constraints for the ensemble. Elgaali and Grasia (2004) investigated the possible effects of climate change on surface water supplies used for irrigation in the Arkansas River basin using ANN model. Dibike and Coulibaly (2006) explained the application of temporal neural networks to downscale the output of global climate models (GCMs). ZeLin et al. (2010) presented a reviewpaper which showed usage of ANN in various fields related to the global warming. Of course, this was not a 'modeling' paper and our primary goal is to investigate changes in temperature during the past 21 years (1990-2010) in San Joaquin River basin in order to calculate the rate of temperature change per year $\left({ }^{\circ} \mathrm{C} /\right.$ year $)$ according to the temperature data collected for these years. At first, we calculated every day's mean temperature to reduce the complications of the problem. Then, we calculated the mean temperature of each year followed by estimating the difference between each year's temperature and the previous years. Then, we divided the results by the difference between those 2 years to get the rate of temperature change $\left({ }^{\circ} \mathrm{C} /\right.$ year). At last, we summarized the calculated rates and divided them by their number (210).

\section{Methods and materials}

A rise in surface water temperature has been observed since the 1960s in Europe, North America and Asia $\left(0.2-2{ }^{\circ} \mathrm{C}\right)$, mainly due to atmospheric warming as a result of increasing solar radiation (Bates et al. 2008). In European rivers Van Vliet and Zwolsman (2008) observed an average increase in water temperature of around $2{ }^{\circ} \mathrm{C}$ in Rhine and Meuse rivers after the severe drought of 2003. Every year, many researchers have been carried out on the issues of climate change and global warming, but because of the importance of these issues, we must update our data on the temperature changing behaviors, and these behaviors should be gradually changed in the course of time. In this paper, we have checked 21-year data related to the San Joaquin River's Old Station, in the form of continuous time series data. Our job was to check the temperature changes continuously and analyze those changes in order to predict future trends as much as possible. The climate is being directly observed by thousands of weather stations; measuring instruments are carried into the upper atmosphere by balloons, kites, airplanes and rockets; merchant ships take measurements of the atmosphere and the oceans; wind profilers, radar systems and other specialized sensors are used; a globally-coordinated fleet of Argo buoys is monitoring sea temperatures and currents; and remote sensing satellites are measuring clouds, temperature, water vapor, atmospheric chemistry, sea level, ice caps, forest cover, and other global climate variables. High-speed telecommunication systems and the Internet distribute vast amounts of data from these instruments to data processing and research centers. These climate observations show a clear warning signal that is greater than what can be attributed to non-human causes (such as volcanoes) (WMO 2013). In this project, we checked more than 735,000 items of temperature $(\mathrm{T})\left({ }^{\circ} \mathrm{C}\right)$ data pertaining to $1990-2010$ of the San Joaquin River's Old Station through continuous time series data in the category of "TB95740" (http:// www.water.ca.govlWaterDataLibraryContinuousTimeSeriesData.htm). They register T data every $15 \mathrm{~min}, 24 \mathrm{~h}$ a day. So, we have $35,040(365 \times 24 \times 4)$ items of $\mathrm{T}$ data for every year and we checked for 21 years. Therefore, we have a total of $735,840(21 \times 35,040)$ items of data to check. But some data are missing (more than 45,000 data, see Table 1). These means that more than $3 \%$ of data was missed, for example, in the year 2005, 17,750 items of data were missed. Therefore, we must regenerate the missing data to get reliable results. To regenerate these data, we have used an ANN model to estimate the missing data. At first, we converted the hourly data into daily data:

To have a better and more accurate ANN model, the degree of relationship between input parameters and the number of data items has the most powerful impact on the precision of the model. Since we use data points on a daily basis and there is very high variation in temperature changes during a day, this issue reduces the strength of
Table 1 The number of missed data for every year

\begin{tabular}{lrrrrrrr}
\hline Year & 2010 & 2009 & 2008 & 2007 & 2006 & 2005 & 2004 \\
\hline Number of missed data & 1 & 0 & 0 & 2 & 2 & 17,570 & 0 \\
Year & 2003 & 2002 & 2001 & 2000 & 1999 & 1998 & 1997 \\
Number of missed data & 0 & 875 & 1132 & 1025 & 6911 & 4848 & 0 \\
Year & 1996 & 1995 & 1994 & 1993 & 1992 & 1991 & 1990 \\
Number of missed data & 0 & 0 & 1921 & 0 & 0 & 2074 & 9161 \\
\hline
\end{tabular}


relationship among data sets. In addition, we must judge temperature variations by using mean data and the mean value of their variations too. In this way, we will be able to use the mean value of daily data $\left(\mathrm{T}_{\mathrm{i}, \mathrm{j}}\right)$ to make a model and evaluate the temperature variations. Therefore, we will have:

$T_{i, j}=\sum_{k=1}^{96} \frac{T_{i, j, k}}{96}$

$T_{i, j}$ : Daily mean value of $\mathrm{T}$ in the $\mathrm{j}$ 'th year and $\mathrm{i}$ 'th day (i ranges from 1 to 365 and j ranges from 1990 to 2010). $T_{i, j, k}$ : Data point of $\mathrm{T}$ in the $\mathrm{j}$ 'th year and $\mathrm{i}$ 'th day and the time of $\mathrm{k}$

As said before, some data is missing. Therefore, to calculate the number and the addresses of $T_{i, j}(s)$, we wrote a visual basic micro program within the Excel software. In this program, we considered a condition that if the data pertaining to a day which is missing; we should suppose the whole data for that day to be missing. On the whole, we have $7665 \mathrm{~T}_{\mathrm{i}, j}(\mathrm{~s})$, but the number of the missing data stands at 493, and we need them to increase the accuracy of our model. The following section explains how to make an ANN model to estimate the missing data.

\section{Model development}

The Neural network method is a modern Technique in the field of engineering that simulates human brain working system. Data recording in human brain occurs through electrochemical massages and brain works as a data processor with parallel structure. It is made up of 1011 related neurons with 1016 connections (Menhaj 2008). The power of memory and senses depend on the dynamic, complicated and constantly changing neuron relations. The intelligence

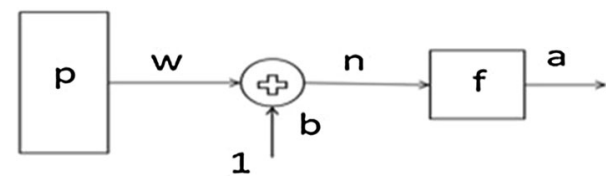

Fig. 1 A simple neuron model and ability of learning by humans is made possible through relations among neurons. A neuron is a nonlinear component of a neural network, serving as a sophisticated nonlinear system with a huge number of nonlinear relations. When a neural network is installed on hardware, the cells that are positioned on a level (layer) can answer simultaneously to all inputs on that level. This peculiarity is the cause of increased processing rate. Each cell operates independently and the total behavior of the network comes from local behaviors of the cells. This property renders local errors ineffective on the output results. In other word, cells correct local errors of the other cells. The neural networks have the ability of dynamic learning and also have parallel structure, so these networks are suitable for controlling problems. In particular, they are used for complicated systems that are impossible or hard to be simulated.

MLF (multi-layer feed-forward) networks trained with back-propagation algorithm are among the most popular kinds of networks (Ehteshami et al. 2016; Salami and Ehteshami 2015, 2016; Tamás 2010; Daniel et al. 1997; Carpenter 1989). Neuron is the smallest data processing unit that is the base of neural networks operations. You can see a single input neuron in Fig. 1, a and $\mathrm{p}$ are the input and the output signals are scalars (vectors). The effect of $\mathrm{P}$ on A is determined by the w scalar (matrix), (Carpenter 1989). Product of this summarization is $n$, which would be the pure input for transfer (activation) function (F), (Chitsazan et al. 2013; Steyl 2009) and so the output of neuron would be calculated as:

$\mathrm{a}=\mathrm{f}(\mathrm{wp}+\mathrm{b})$

The parameters $b$ and $w$ are adjustable and the activation function can be also chosen by the designer of the network. Training means that $\mathrm{b}$ and $\mathrm{w}$ would change many times in a direction to get closer to a desired relation between inputs and outputs. The activation function (f) can be linear or non-linear. Function (f) would be chosen according to the defined problem. A few sample functions are shown in Fig. 2.

A neuron normally has more than one input. Figure 3 shows a neuron that has a number of $\mathrm{R}$ inputs. The input

Fig. 2 Transfer functions
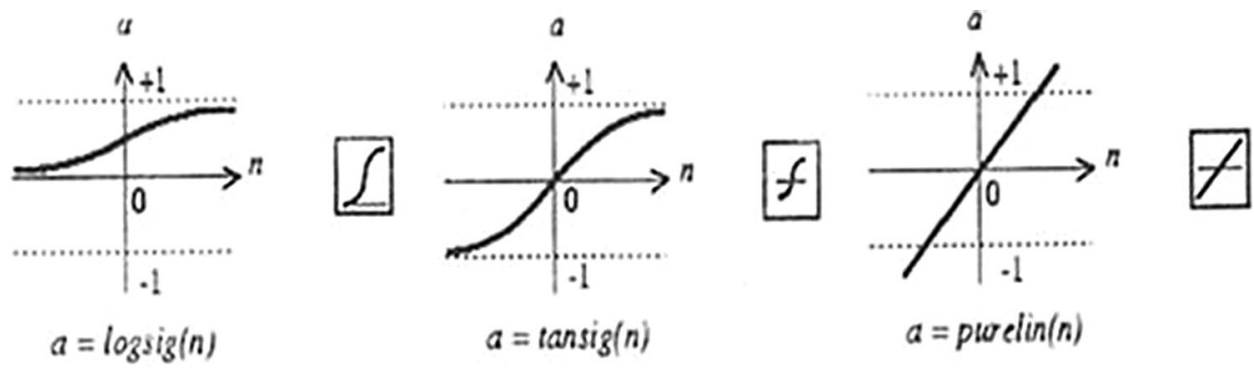
vector is shown by $\mathrm{p}$, while pi $(\mathrm{i}=1,2 \ldots \mathrm{R})$ Values are the elements of this vector. Wis is compounding the weight matrix. All of the elements of $p$ vector multiply in the related element of w matrix to form the bios (b), (Abraham 2005; Menhaj 2008).

The input (n) calculated as:

$\mathrm{n}=\sum_{i=1}^{R} \mathrm{p}_{\mathrm{i}} \mathrm{w}_{1, \mathrm{i}}+\mathrm{b}=[\mathrm{w}] \cdot \mathrm{p}+\mathrm{b}$

and:

$\mathrm{p}=\left[\mathrm{p}_{1}, \mathrm{p}_{2}, \ldots, \mathrm{p}_{\mathrm{R}}\right]^{\mathrm{T}}, \mathrm{w}=\left[\mathrm{w}_{1,1}, \ldots, \mathrm{w}_{1, \mathrm{R}}\right]$

And the form of the output will be like below:

$\mathrm{a}=\mathrm{f}(\mathrm{w} \cdot \mathrm{p}+\mathrm{b})$

A single layer network with $\mathrm{S}$ neurons and $\mathrm{R}$ inputs is shown in Fig. 4.

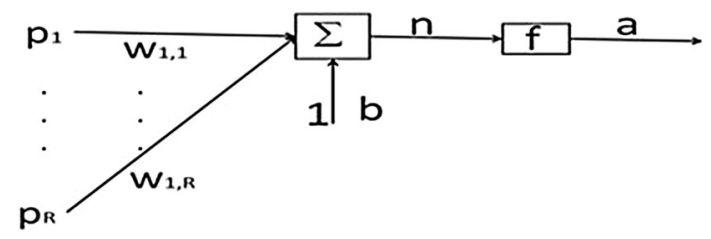

Fig. 3 A neuron with $\mathrm{R}$ inputs

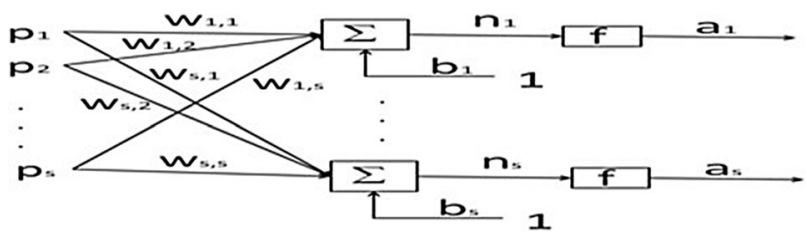

Fig. $4 \mathrm{~S}$ neuron with $\mathrm{R}$ inputs

\section{Learning rules}

We define the learning rule as a process for correcting (improving) weights and biases. We have two kinds of learning rules (functions): supervised and unsupervised. In the supervised mode, e.g. perceptron, we compare the network output with learning examples (which is related to the input data). Unsupervised learning method is being used mainly for division problems.

\section{Feed-forward networks}

Architecture of the network: A basic architecture contains three types of layers: input layer, hidden layer and output layer. The input layer is responsible for introducing input data, and hidden layer(s) is a place for performing processes. The output layer produces the results (Rounds 2002; Fausett 1994; Dowla and Rogers 1995; Gurney 1999; Haykin 1994; Patterson 1996). In Fig. 5, a five-layer feed forward network with three hidden layers is demonstrated. Each layer can contain different numbers of neurons.

In the feed-forward networks data stream signal always goes straight forward, from the input side to the output site. The process can be done in many units (i.e., layers) (Chitsazan et al. 2013). And we don't have a return data stream here. For training by constant stream of data, network changes weights and biases in each step and compares the output layer with answers (supervised mode). In the next step of training, weights and biases are changed to minimize the error. You would see a two-layer (tansig/pureline) network in Fig. 6. This network can be used for estimating any function with any number of rupture points.

Fig. 5 A network with five layers

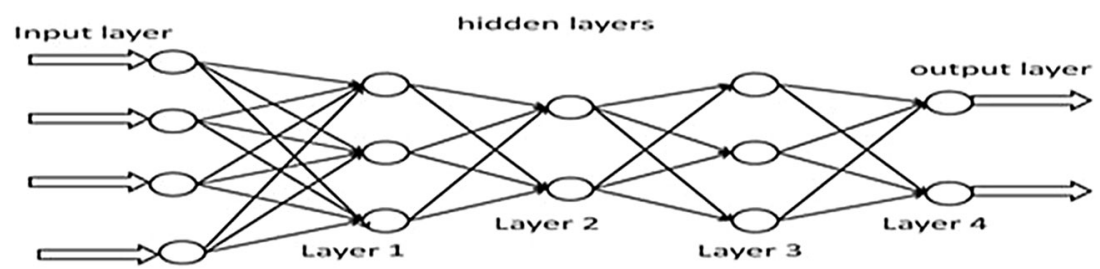

Fig. 6 A three-layer feedforward network

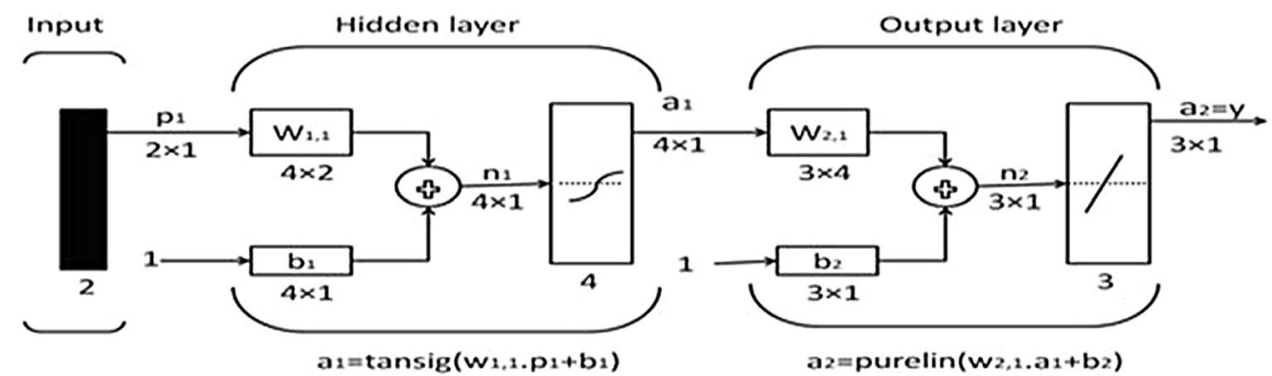


Table 2 Design parameters of optimum NETWORK

\begin{tabular}{|c|c|c|c|}
\hline Number of layers & 4 & A & 0.001 \\
\hline Number of neurons in each layer & $25,25,25^{(1)}$ & $\alpha-\operatorname{dec}$ & 0.1 \\
\hline Training algorithm & LM & $\alpha$-inc & 10 \\
\hline Transfer function & Tansign & $\alpha-\max$ & 1010 \\
\hline Performance function & Mse & epoches & 1000 \\
\hline Adaption learning function & Learngdm ${ }^{(2)}$ & Goal(Error) & 0 \\
\hline
\end{tabular}

\section{Results and discussion}

To start the calculations, we can use a two-layer model. Then, we calibrate weight and bias matrixes (by guessing) as follows according to (Menhaj 2008; Syozil et al. 1997). To reduce the error and have the required precision, $\alpha$ is the learning rate $(\alpha>0)$ and the number of each step could be one:

$w_{i, j}^{(l+1)}=w_{i, j}^{(l)}-\alpha \frac{\partial e(w, b)}{\partial w_{i, j}^{(l)}}$

$b_{i, j}^{(l+1)}=b_{i, j}^{(l)}-\alpha \frac{\partial e(w, b)}{\partial b_{i, j}^{(l)}}$

$\frac{\partial e(w, b)}{\partial w_{i . j}^{(l)}}=\left[\frac{1}{m} \sum_{i=1}^{m} \frac{\partial}{\partial w_{i . j}^{(l)}} e\left(w, b ; x^{i}, y^{(i)}\right)\right]+\alpha w_{i, j}^{(l)}$

$\frac{\partial e(w, b)}{\partial b_{i, j}^{(l)}}=\left[\frac{1}{m} \sum_{i=1}^{m} \frac{\partial}{\partial b_{i, j}^{(l)}} e\left(w, b ; x^{i}, y^{(i)}\right)\right]+\alpha b_{i, j}^{(l)}$

The scale of precision (in supervised mode) will be the quantity of mean square error (MSE) where ti is the answer (matrix) and ai (matrix) is the output of the network:

mse $=\frac{1}{m} \sum_{i=1}^{m} e^{2}=\frac{1}{m} \sum_{i=1}\left(t_{i}-a_{i}\right)^{2}$

MATLAB is used for calculations (Chitsazan et al. 2013; Chu et al. 2013). We found optimum conditions for designing the model, which are shown in Table 2.

We took two major parameters, namely the year (i) and the number of days (in that year) (j), as input data and the $\mathrm{Ti}, \mathrm{j}$ (s) as output data. By doing this, we can input the address (es) of the missed data in the model and the model will give us the missed Ti, $\mathrm{j}$ (s). After making the model, we choose one data series from each year to test the model. The model's results and the real data have been shown in Table 3 and Fig. 7, which can also indicate the efficiency and accuracy of the model:

The results produced by the model are very close to the real data (Fig. 7) and the mean error is 0.02 , which is very low and makes our model seem very reliable. Our model is very precise, but in some years, like 2005, more than half
Table 3 The model results and pilot data

\begin{tabular}{rrrrr}
\hline Year & Day & Pilot Tij & Estimated Tij & \multicolumn{1}{c}{ Eror } \\
\hline 2010 & 11 & 18.06 & 18.22 & -0.15 \\
2009 & 254 & 21.80 & 21.87 & -0.08 \\
2008 & 114 & 8.98 & 8.42 & 0.56 \\
2007 & 102 & 8.31 & 7.50 & 0.81 \\
2006 & 91 & 11.53 & 11.35 & 0.17 \\
2005 & 32 & 6.36 & 6.57 & -0.22 \\
2004 & 300 & 26.84 & 26.95 & -0.11 \\
2003 & 256 & 21.92 & 22.41 & -0.49 \\
2002 & 271 & 24.76 & 25.12 & -0.36 \\
2001 & 69 & 11.95 & 11.82 & 0.13 \\
2000 & 53 & 15.94 & 16.18 & -0.23 \\
1999 & 321 & 18.40 & 18.36 & 0.04 \\
1998 & 68 & 11.30 & 11.40 & -0.09 \\
1997 & 110 & 8.08 & 8.04 & 0.04 \\
1996 & 307 & 26.21 & 25.44 & 0.77 \\
1995 & 85 & 8.20 & 8.71 & -0.51 \\
1994 & 105 & 7.22 & 8.18 & -0.96 \\
1993 & 116 & 10.72 & 9.88 & 0.84 \\
1992 & 169 & 15.46 & 15.84 & 0.40 \\
1991 & 62 & 7.35 & 7.03 & \\
1990 & 153 & 10.23 & 9.83 & \\
\hline
\end{tabular}

of the needed data is missing and the other half (or existing) data shows abnormal changes, which directly impact the model's results. But being smart enables this model to maintain the mean value of all the data permanently, as is evident by very small amount of error that it makes. So, we can trust the model results and calculate the amount and the rate of temperature changes with the help of the data generated by the model. In another case, to make sure about its precision for the years 1999, 1998, 1990 and 2005, which account for the highest amount of missed data, we removed them from the data schedule and carried out the calculations without them. After making sure about the model's precision, we can regenerate the missed $T_{i, j}(s)$ by using the model and to do that, we enter missed data addresses into the model. After regenerating the missing data, we placed every set of data in its right place (using a 
micro program within the Excel environment). The mean temperature for every year has been shown in the following Table 4 and Fig. 8.

Now we have all the data we need. There are many ways to calculate the rate $(\mathrm{R})$ of temperature change per year $\left({ }^{\circ} \mathrm{C} /\right.$ year). Table 5 shows the simulation results. However, in our opinion, the best way is to calculate the difference between every year's mean temperature and other years. Then, we must divide the result (value) to the time interval that separates those 2 years according to the following formula:

$R_{i, j}=\frac{T_{i}-T_{j}}{i-j} ; i>j ; 1990 \geq i, j \geq 2010$

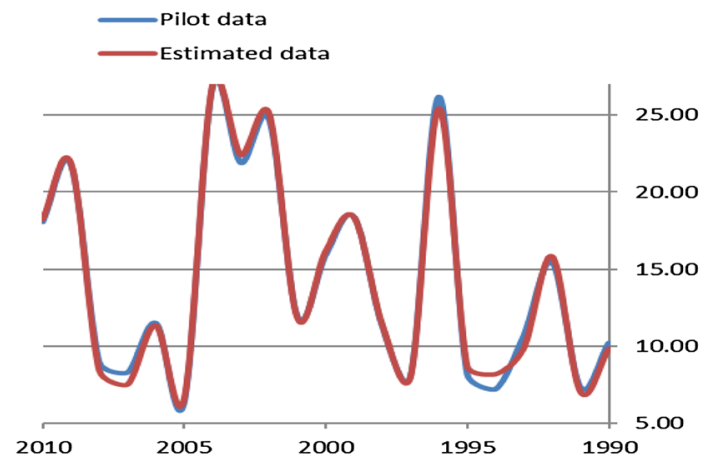

Fig. 7 Pilot and estimated data

Table 4 The mean temperature for every year

\begin{tabular}{llllllll}
\hline Year & 2010 & 2009 & 2008 & 2007 & 2006 & 2005 & 2004 \\
\hline $\mathrm{Tm}_{\mathrm{i}}$ & 16.76 & 18.00 & 17.62 & 17.50 & 16.48 & 19.19 & 17.80 \\
Year & 2003 & 2002 & 2001 & 2000 & 1999 & 1998 & 1997 \\
$\mathrm{Tm}_{\mathrm{i}}$ & 18.16 & 18.04 & 17.50 & 16.52 & 13.20 & 15.99 & 17.47 \\
Year & 1996 & 1995 & 1994 & 1993 & 1992 & 1991 & 1990 \\
$\mathrm{Tm}_{\mathrm{i}}$ & 17.29 & 16.14 & 17.55 & 17.58 & 18.43 & 16.77 & 15.57 \\
\hline
\end{tabular}

$T_{i}$ : The mean temperature in year i $\left({ }^{\circ} \mathrm{C}\right), R_{i, j}$ : The rate of variation in the i'th year's temperature compared to the $\mathrm{j}$ 'th year's temperature $\left({ }^{\circ} \mathrm{C} /\right.$ year $)$.

Now we can summarize all the $R_{i, j}$ (s) and then divide the result to the number of existing $R_{i, j}(s)$ :

$R=\frac{\sum_{i=1990}^{2010} \sum_{j=1990}^{2010} R_{i, j}}{n} ; i>j$

$R$ : Rate of the temperature change according to 1990 2010 data $n$ : Number of existing conditions for $i>j\left(\mathrm{R}_{\mathrm{i}, \mathrm{j}}\right.$ (S)) which equals to 210 . And we will have $\mathrm{R}=0.0354$ $\left({ }^{\circ} \mathrm{C} /\right.$ year $)$.

\section{Conclusion}

According to the current research study and also the values given in the Table 5, $\mathrm{R}$ will be equal to $0.0354\left({ }^{\circ} \mathrm{C} /\right.$ year), which means that if the existing conditions continue in the way they did during the past 20 years, we will have a temperature rise of about $3.54{ }^{\circ} \mathrm{C}$ during the next 100 years. There is no need to explain that this amount of temperature rise is very high and may pose a serious threat to the life of humans and other creatures on earth. IPCC presented a model that estimated temperature changes during the current century will be:

- 2.6-4.6 ${ }^{\circ} \mathrm{C}$ for low predictions, and

- 3.7-6.5 ${ }^{\circ} \mathrm{C}$ for high predictions (Meehl and Stocker 2007).

Our result also matches the IPCC model. A more important issue is that the rate of temperature changes in the San Joaquin River basin is higher than the global value. In addition, we observed that how ANN models can be used for accurate regeneration of the missing data. Our
Fig. 8 The mean temperature for every year

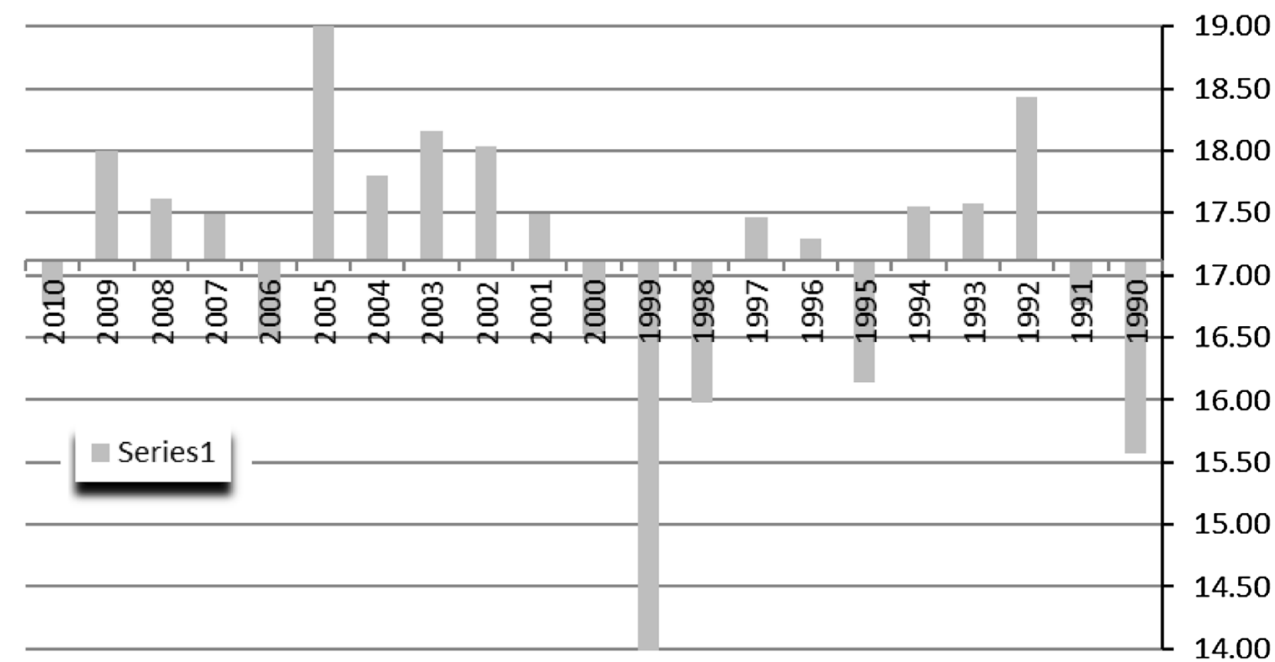


Table 5 The rate of temperature variation per year $\mathrm{Ri}, \mathrm{j}(\mathrm{s})\left({ }^{\circ} \mathrm{C} / \mathrm{Year}\right)$

\begin{tabular}{lllllllllllllll}
\hline Year & 2009 & 2008 & 2007 & 2006 & 2005 & 2004 & 2003 & 2002 & 2001 & 2000 & 99 & 98 & 97 & 96 \\
\hline 2010 & -1.24 & -0.4 & -0.2 & 0.07 & -0.53 & -0.17 & -0.2 & -0.16 & -0.1 & 0.02 & 0.32 & 0.02 & -0.1 & -0 \\
2009 & - & 0.38 & 0.25 & 0.5 & -0.36 & 0.04 & -0 & -0.01 & 0.06 & 0.16 & 0.48 & 0.14 & 0.04 & 0.05 \\
2008 & - & - & 0.12 & 0.57 & -0.6 & -0.04 & -0.1 & -0.07 & 0.02 & 0.14 & 0.49 & 0.11 & 0.01 & 0.03 \\
2007 & - & - & - & 1.01 & -0.96 & -0.1 & -0.2 & -0.11 & 0 & 0.14 & 0.54 & 0.11 & 0 & 0.02 \\
2006 & - & - & - & - & -2.94 & -0.66 & -0.6 & -0.39 & -0.2 & -0 & 0.47 & -0 & -0.1 & -0.1 \\
2005 & - & - & - & - & - & 1.626 & 0.63 & 0.46 & 0.48 & 0.58 & 1.04 & 0.42 & 0.24 & 0.24 \\
2004 & - & - & - & - & - & - & -0.4 & -0.12 & 0.1 & 0.32 & 0.92 & 0.22 & 0.05 & 0.06 \\
2003 & - & - & - & - & - & - & - & 0.12 & 0.33 & 0.55 & 1.24 & 0.33 & 0.11 & 0.12 \\
2002 & - & - & - & - & - & - & - & - & 0.54 & 0.76 & 1.61 & 0.39 & 0.11 & 0.12 \\
2001 & - & - & - & - & - & - & - & - & - & 0.97 & 2.15 & 0.33 & 0.01 & 0.04 \\
2000 & - & - & - & - & - & - & - & - & - & - & 3.32 & 0.01 & -0.3 & -0.2 \\
1999 & - & - & - & - & - & - & - & - & - & - & - & -3.3 & -2.1 & -1.4 \\
1998 & - & - & - & - & - & - & - & - & - & - & - & - & -1 & -0.4 \\
1997 & - & - & - & - & - & - & - & - & - & - & - & - & - \\
\hline
\end{tabular}

research highlights is as follows: (1) we represent a new formula (number 11) to show the average rating of temperature changing. (2) we use an ANN model to regenerate missing data. And (3) it is the first time that the temperature study was performed in the current area.

Acknowledgments The authors are grateful to Dr. Mohamad Rabbani for their editorial and revision assistance. Also, they are thankful of San Joaquin River Monitoring Stations Control Board for providing data for the current analyses.

\section{References}

Abraham A (2005) Artificial neural networks. Oklahoma State University, Stillwater, pp 901-908

Anderegga WRL, Prallb JW, Haroldc J, Schneider SH (2010) Expert credibility in climate change, PNAS. Proc Natl Acad Sci USA 107(27):12107-12109

Arnell NW (2004) Climate change and global water resources: SRES emissions and socio-economic scenarios. Glob Environ Change $14: 31-52$

Bates BC, Kundzewicz ZW, Wu S, Palutikof JP (eds) (2008) Climate change and water. Technical paper of the intergovernmental panel on climate change. iPCC Secretariat Geneva 210

Carpenter GA (1989) Neural network models for pattern recognition and associative memory. J Neural Netw 2:243-257

Chitsazan M, Rahmani G, Neyamadpour A (2013) Groundwater level simulation using artificial neural network: a case study from Aghili plain, urban area of Gotvand, South-West Iran. J Geope 3(1):35-46

Chu HB, Lu WX, Zhang L (2013) Application of artificial neural network in environmental water quality assessment. J Agr Sci Tech 15:343-356

Daniel S, Vladimír K, Jiří P (1997) Introduction to multi-layer feedforward neural networks. Chemom Intell Lab Syst 39:43-62

Delpla I, Jung AV, Baures E, Clement M, Thomas O (2009) Impacts of climate change on surface water quality in relation to drinking water production. Environ Int 35:1225-1233
Dibike YB, Coulibaly P (2006) Temporal neural networks for downscaling climate variability and extremes. Neural Netw 19:135-144

Doran PT, Zimmerman MK (2009) Examining the scientific consensus on climate change. EOS 90(3):20-22

Dowla UF, Rogers L (1995) Solving problems in environmental engineering and geosciences with artificial neural networks. MIT Press, Massachusetts, USA

Ehteshami M, Biglarijoo N (2014) Determination of nitrate concentration in groundwater in agricultural area in Babol County. Iran J Health Sci 2(4):1-9

Ehteshami M, Peralta RC, Eisele H, Deer H, Tindall T (1991) Assessing pesticide contamination to ground water: a rapid approach. J Ground Water 29(6):862-886

Ehteshami M, Dolatabadi Farahani N, Tavassoli S (2016) Simulation of nitrate contamination in groundwater using artificial neural networks. J Model Earth Syst Environ 2(28):1-10

Elgaali E, Grasia L (2004) Neural network modeling of climate change impact on irrigation water supplies in Arkansas river basin. Hydrol Days 67-84

Fausett L (1994) Fundamentals of neural networks architectures. Algorithms and applications. Prentice Hall, USA

Gurney K (1999) An introduction to neural network. UCL Press, UK

Gutzler D (2007) Climate change and water resources in New Mexico. N M Earth Matters; A Division of New Mexico Tech $1-6$

Haykin S (1994) Neural networks: a comprehensive foundation. Macmillan, New York

Hilbert DW, Ostendorf B (2001) The utility of artificial neural networks for modelling the distribution of vegetation in past. Present and future climates. Ecol Model 146:311-327

IPCC Intergovernmental Panel on Climate change. IPCC Secretariat (2011) America's climate choices. The National Academies Press, Washington D.C 15

Knutti R, Stocker TF, Joos F, Plattner GK (2003) Probabilistic climate change projections using neural networks. Clim Dyn $21: 257-272$

Mann ME (2009) Do global warming and climate change represent a serious threat to our welfare and environment. Social Philosophy and Policy Foundation, pp 193-231

Meehl GA, Stocker TF (2007) Global climate projections, Chap. 10: Sec. 10. ES: mean temperature. In: IPCC AR4 WG1 
Memzel L, Matovelle A (2010) Current state and future development of blue water availability and blue water demand: a view at seven case studies. J Hydrol 384:245-263

Menhaj MB (2008) Fundamental of neural network, vol 1. Industrial Amir Kabir University, Tehran

Patterson D (1996) Artificial Neural networks. Prentice Hall, Singapore

Rounds SA (2002) Development of a neural network model for dissolved oxygen in the Tualatin River. Oregon Second Federal Interagency Hydrologic Modeling Conference Las Vegas Nevada July 29-August 1, pp 1-13

Salami ES, Ehteshami M (2015) Simulation, evaluation and prediction modeling of river water quality properties (Case study: Ireland Rivers). Int $\mathbf{J}$ Eng Sci Technol (Springer) 12(10):3235-3242. doi:10.1007/s13762-015-0800-7

Salami ES, Ehteshami M (2016) Application of artificial neural networks to estimating DO and salinity in San Joaquin River basin. Desalin Water Treat 57(11):4888-4897. doi:10.1080/ 19443994.2014.995713

Steyl G (2009) Application of artificial neural networks in the field of geohydrology. University of the Free State, South Africa

Syozil D, Kvasni EV, Pospichal J (1997) Introduction to multi-layer feed-forward neural networks. Chemo Metrics Intell Lab Syst $39: 43-62$
Tamás K (2010) The application of neural networks for solving complex optimization problems in modeling. Conf Jr Res Civ Eng, 97-102

Trigo RM, Palutikof JP (1999) Simulation of daily temperatures for climate change scenarios over Portugal: a neural network model approach. Climate Res 13:45-59

Van Vliet MTH, Zwolsman JJG (2008) Impact of summer droughts on the water quality of the Meuse River. J Hydrol 353:1-17

WMO (2013) A summary of current climate change findings and figures. WMO. http://www.unep.org/climatechange/Publications/ Publication/tabid/429/language/en-US/Default.aspx ?ID=6306

Yousefi M, Ehteshami M, Sadrnejad SA (2015) Lead contamination and pollution indexes in roadside soil in Tehran Iran. Iran $\mathbf{J}$ Health Sci 3(4):8-23

Ze Lin L, Chang Hui P, Wen Hua X, Da Lun T, Xiang Wen D, Mei Fang Z (2010) Application of artificial neural networks in global climate change and ecological research: an overview. 55(34):3853-3863. Science China Press and Springer-Verlag, Berlin, Heidelberg

Zwolsman JJG, Van Bokhoven AJ (2007) Impact of summer droughts on water quality of the Rhine River-a preview of climate change. Water Sci Technol 56:44-55 